\title{
Knockdown of the Bmi-1 oncogene inhibits cell proliferation and induces cell apoptosis and is involved in the decrease of Akt phosphorylation in the human breast carcinoma cell line MCF-7
}

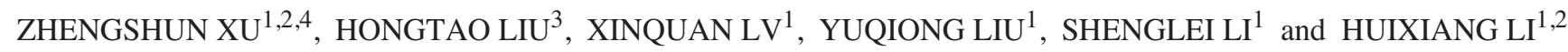 \\ ${ }^{1}$ Department of Pathology, The First Affiliated Hospital, ${ }^{2}$ Department of Pathology, College of Basic Medical Science, \\ ${ }^{3}$ Laboratory for Cell Biology, Department of Bioengineering, Zhengzhou University, Zhengzhou, \\ Henan 450052; ${ }^{4}$ Department of Pathology, Medical College of Henan University \\ of Science and Technology, Luoyang, Henan 471003, P.R. China
}

Received August 20, 2010; Accepted September 29, 2010

DOI: $10.3892 /$ or.2010.1078

\begin{abstract}
It is well documented that B cell-specific Moloney murine leukemia virus integration site 1 (Bmi-1), widely overexpressed in the vast majority of malignancies, plays an essential role in the occurrence and development of several different tumors. Here, we report Bmi-1 siRNA-mediated cell proliferation inhibition and cell apoptosis in vitro and in vivo in the human breast carcinoma cell line $\mathrm{MCF}-7$. Our results demonstrated that Bmi-1 siRNA effectively down-regulated the expression of Bmi-1, inhibited cell proliferation in vitro and in vivo, evoked cell cycle arrest in the $\mathrm{G}_{0} / \mathrm{G}_{1}$ phase and induced cell apoptosis in MCF-7 cells, coupled with decrease in cyclin D1, cyclin E, cdk2, bcl-2 and Ki-67 expression and Akt phosphorylation levels and an increase of p21 and bax expression and activities of caspase-3/-9. Taken together, our results suggest that Bmi-1 may be a potential molecular target for the therapy of breast carcinoma.
\end{abstract}

\section{Introduction}

Breast carcinoma is the most common malignancy diagnosed among women and is the leading cause of cancer death worldwide (1). In 2000 alone, more than one million women were diagnosed and 373,000 women died of breast carcinoma (1). In the past few decades, the incidence of breast carcinoma has increased steadily, but the mortality of breast carcinoma seems to be declining (2), suggesting a benefit from the progression of early diagnosis and effective treatment.

Correspondence to: Dr Shenglei Li or Professor Huixiang Li, Department of Pathology, The First Affiliated Hospital of Zhengzhou University, 40 Daxue Road, Zhengzhou, Henan 450052, P.R. China

E-mail: 1slbljys@126.com

E-mail: 1hxbljys@126.com

Key words: Bmi-1, siRNA, cell apoptosis, Akt phosphorylation, breast carcinoma
However, to date, the etiology of most breast carcinoma cases remains ill-defined, and the molecular mechanisms underlying the development and progression of breast carcinoma are complex and vary among individual tumors (3). Therefore, a better understanding of the molecular mechanisms in development and progression of breast carcinoma helps to improve the survival and prognosis of patients with breast carcinoma, providing the theoretical basis for molecular target therapy of the patients with breast carcinoma.

Polycomb group ( $\mathrm{PcG}$ ) proteins, as epigenetic gene silencers, play a pivotal role in the occurrence and development of tumors (4). Bmi-1, the first identified PcG gene, has been documented to be involved in multiple biological processes, such as embryonic development, organ formation, tumorigenesis, stem cell stabilization and differentiation (5). With the rapid development of molecular biology and oncology, more and more evidence has shown that Bmi-1 is tightly associated with the development of tumors, including non-small cell lung cancer (6), colorectal cancer (7), nasopharyngeal carcinoma (8), oral cancer (9), esophageal squamous cell carcinoma $(10)$, breast carcinoma $(11,12)$. However, detailed molecular mechanism of Bmi-1 in occurrence and development of breast carcinoma remains to be elucidated. Therefore, in the current study, Bmi-1 siRNA was used to down-regulate the expression of Bmi-1 in breast carcinoma, followed by analysis of cell proliferation and detection of cell apoptosis in vitro and in vivo. Further, expressions of cell cycle regulatory genes including cyclin D1, cyclin E, cdk2 and p21 and cell apoptosis related genes such as bcl-2 and bax were investigated by semi-quantitative RT-PCR and Western blotting methods, and activities of caspase-3/-9 and expression of Ki-67 were detected. The findings presented herein will provide the first new data for future gene therapy of breast carcinoma.

\section{Materials and methods}

Cell line and cell culture. Breast carcinoma cell line MCF-7 cells (human breast epithelial carcinoma) were purchased from the Institute of Medical Biotechnology, Chinese Academy of 
Table I. Primers used for semi-quantitative RT-PCR analysis.

\begin{tabular}{|c|c|c|c|c|}
\hline Genes & Primers & Size (bp) & $\begin{array}{c}\text { Annealing } \\
\text { temperature }\left({ }^{\circ} \mathrm{C}\right)\end{array}$ & Accession no \\
\hline cyclin D1 & $\begin{array}{l}\text { F: 5'-GCCCGAGGAGCTGCTGCAAA-3' } \\
\text { R: 5'-CCTGGCGCAGGCTTGACTCC-3' }\end{array}$ & 386 & 55 & NM_053056 \\
\hline cyclin E & $\begin{array}{l}\text { F: 5'-GCGGAGTTCTCGGCTCGCTC-3' } \\
\text { R: 5'-AGCGGGGAGCCTCTGGATGG-3' }\end{array}$ & 251 & 55 & NM_001238 \\
\hline cdk2 & $\begin{array}{l}\text { F: 5'-TTCCAGCTGCTCCAGGGCCT-3' } \\
\text { R: 5'-CCGGGCCCACTTGGGGAAAC-3' }\end{array}$ & 309 & 54 & NM_052827 \\
\hline bcl-2 & $\begin{array}{l}\text { F: 5'-CGGTGCCACCTGTGGTCCAC-3' } \\
\text { R: 5'-TCCCCCAGTTCACCCCGTCC-3' }\end{array}$ & 174 & 54 & NM_000633 \\
\hline bax & $\begin{array}{l}\text { F: 5'-CTGGACCCGGTGCCTCAGGA-3' } \\
\text { R: 5'-GAGTCTGTGTCCACGGCGGC-3' }\end{array}$ & 122 & 55 & NM_138764 \\
\hline B-actin & $\begin{array}{l}\text { F: 5'-TATGTGGGCGACGAGGCCCA-3' } \\
\text { R: 5'-GGAGCTGGAAGCAGCCGTGG-3' }\end{array}$ & 546 & 55 & NM_001101 \\
\hline
\end{tabular}

Medical Sciences, and were maintained in RPMI-1640 medium (Gibco, USA) supplemented with $10 \%$ fetal bovine serum (FBS) (HyClone Laboratories, Logan, USA), $100 \mathrm{U} / \mathrm{ml}$ penicillin and $100 \mu \mathrm{g} / \mathrm{ml}$ streptomycin at $37^{\circ} \mathrm{C}$ in the presence of $5 \% \mathrm{CO}_{2}$.

Bmi-1 siRNA and control siRNA transfection. Bmi-1 siRNA and control siRNA (Santa Cruz Co., CA, USA) at a concentration of $100 \mathrm{nM}$ were transfected into $\mathrm{MCF}-7$ cells, respectively. MCF-7 cells were culutred at $37^{\circ} \mathrm{C}$ in a $\mathrm{CO}_{2}$ incubator until the cells are $60-80 \%$ confluent, subsequently, the cells were transfected with Lipofectamine ${ }^{\mathrm{TM}} 2000$ (Invitrogen) according to manufacturer's instructions. The transfection reagent $(10 \mu 1)$ and Bmi-1 siRNA or control siRNA (6 $\mu 1$ each) were incubated with MCF-7 cells in RPMI-1640 culture (serum-free media) for $6 \mathrm{~h}$, and then complete media were used to culture further $48 \mathrm{~h}$ for experiments below.

CCK-8 for cell proliferation assay. Cell proliferation was determined using WST-8 dye (Beyotime Institute of Biotechnology, China) according to manufacture's instructions. Briefly, $5 \times 10^{3} \mathrm{MCF}-7$ cells/well was seeded in a 96-well cell culture plate, grown at $37^{\circ} \mathrm{C}$ for $24 \mathrm{~h}$, and then placed in serumstarved conditions for a further $6 \mathrm{~h}$. Subsequently, MCF-7 cells were transfected with Bmi-1 siRNA and control siRNA, respectively. On the day of measuring the growth rate of untreated and transfected cells $(24,48,72$ and $96 \mathrm{~h}$, respectively), $100 \mu 1$ of spent medium was replaced with an equal volume of fresh medium containing $10 \%$ CCK-8, then cells were continued to incubate at $37^{\circ} \mathrm{C}$ for $3 \mathrm{~h}$, and the absorbance was finally determined at $450 \mathrm{~nm}$ using Microplate reader.

Cell cycle analysis by flow cytometry. Cell cycle was performed using flow cytometry according to previous published methods (13). Briefly, $1 \times 10^{6}$ of untreated and transfected MCF-7 cells were harvested and washed in PBS, then fixed in $70 \%$ cold ethanol for $30 \mathrm{~min}$ at $4^{\circ} \mathrm{C}$. After washing in cold PBS thrice, cells were resuspended in $1 \mathrm{ml}$ of PBS solution with $40 \mu \mathrm{g}$ of propidium iodide and $100 \mu \mathrm{g}$ of RNase A for $30 \mathrm{~min}$ at $37^{\circ} \mathrm{C}$. Finally, samples were subjected to analysis of their DNA contents by BectonDickinson FACScan Flow Cytometer (FAC Scan, BectonDickinson, Mountain View, USA). CellQuest software was used for acquisition and analysis of the data, and the percentage of cells in each phase was determined.

Cell apoptosis detection. MCF-7 cells untreated and transfected with control siRNA and Bmi-1 siRNA were trypsinized, washed with cold PBS buffer, and then resuspended in PBS buffer, respectively. Annexin V-FITC (BD Biosciences, USA) at final concentration of $1 \mu \mathrm{g} / \mathrm{ml}$ and $250 \mathrm{ng}$ of propidium iodide were added to a mixture containing $100 \mu 1$ of cell resuspension and binding buffer (BD Biosciences) each. After cells were vortexed and incubated for $15 \mathrm{~min}$ at room temperature (RT) in the dark, $400 \mu 1$ of binding buffer was added to the mixture for flow cytometric analysis. CellQuest software was used for acquisition and analysis of the data, and the percentage of cell apoptosis was determined.

Measurement of caspases activity. MCF-7 cells untreated and transfected with control siRNA and Bmi-1 siRNA were harvested and centrifuged at $1200 \mathrm{rpm}$ for $10 \mathrm{~min}$, respectively. Cells were washed two times with PBS (pH 7.4) and then resuspended with $50 \mu 1$ lysis buffer at $4^{\circ} \mathrm{C}$ and incubated on ice for $10 \mathrm{~min}$. All the following steps were performed on ice. Cell extracts $(30 \mu \mathrm{g})$ were diluted to $100 \mathrm{ml}$ with $50 \mu \mathrm{l}$ of $2 \mathrm{x}$ reaction buffer (40 mM PIPES, pH 7.2, $200 \mathrm{mM} \mathrm{NaCl}, 2 \mathrm{mM}$ EDTA, $0.2 \%$ CHAPS, $20 \%$ sucrose and $20 \mathrm{mM}$ DTT), and incubated for $30 \mathrm{~min}$ at $37^{\circ} \mathrm{C}$ with $10 \mu \mathrm{M}$ of fluorogenic caspase substrates of caspase-3 and -9 (Ac-DEVD-AMC and Ac-LEHD-AFC), respectively. After overnight incubation in dark at $37^{\circ} \mathrm{C}$, samples were read in a microplate reader at $405 \mathrm{~nm}$. The data represent the mean \pm SD from three separate experiments. The results are expressed as fold induction. 
Semi-quantitative RT-PCR. Total RNAs were extracted from MCF-7 cells untreated and transfected with control siRNA and Bmi-1 siRNA by TRIzol reagent (Invitrogen) according to the manufacturer's instructions, and then subjected to firststrand cDNA synthesis with AMV first strand DNA synthesis kit (Biotech Co., Shanghai, P.R. China). Primers in Table I were used to amplify the specific band using the procedures described as follows: initial denaturation at $94^{\circ} \mathrm{C}$ for $2 \mathrm{~min}$, followed by $30 \mathrm{sec}$ at $94^{\circ} \mathrm{C}, 30 \mathrm{sec}$ at different genes annealing temperatures (Table I), and $30 \mathrm{sec}$ at $72^{\circ} \mathrm{C}$ for a total of 30 cycles and a terminal extension at $72^{\circ} \mathrm{C}$ for $6 \mathrm{~min}$. After amplification, $10 \mu \mathrm{l}$ of PCR products were resolved on a $1 \%$ agarose gel. DNA bands were visualized by UV light and documented with a Gene Tools (Model P67UA). Semi-quantitative analysis of Band intensity was performed with Gene Tools software (UVP, Inc., Upland, USA).

Western blot analysis. Western blotting was performed according to published methods (14). Briefly, MCF-7 cells untreated and transfected with control siRNA and Bmi-1 siRNA were harvested and lysed for $20 \mathrm{~min}$ in cold lysis buffer. Protein concentrations were determined with standard Bradford method. Equal amounts of protein (60 $\mu \mathrm{g} /$ lane) for each sample were electrophoresed through a $10 \%$ SDS-PAGE gel, and then electro-transferred to nitrocellulose membranes (Amersham, Uppsala, Sweden) by a semi-dry transferor. The membranes were blocked in 5\% skimmed milk in PBS-T containing $0.05 \%$ Tween-20 at RT for $2 \mathrm{~h}$, and then incubated at RT for $2 \mathrm{~h}$ with corresponding primary antibodies including anti-Bmi-1, anti-cyclin D1, anti-cyclin E, anti-cdk2, anti-p21, anti-bcl-2, anti-bax, anti-Ki-67, anti-Akt, antiphospho-Akt at Ser308, anti-phospho-Akt at Ser473 and antiB-actin (all from Santa Cruz, Co.) diluted in 1\% skimmed milk in PBS-T, respectively, followed by incubation with horseradish peroxidase-conjugated secondary antibodies (antigoat, anti-rabbit or anti-mouse) (Santa Cruz, Co.). For detection, DAB solution was used to develop the bands of specific proteins on the membranes according to manufacturer's instructions. Quantification of band intensity was performed using Gene Tools (UVP, Inc.).

Tumorigenicity in nude mice. All animal studies were performed in compliance with the Guide for the Care and Use of Laboratory Animals of Henan Province, China. Male athymic BALB/c nude mice (Vital River Animal Ltd., Beijing, China) at 4-5 weeks of age were used in the study. The conditions of animals-farming were prepared according to previous published method (15). MCF-7 cells were dissociated with trypsin-EDTA and suspended in PBS at a density of $\left(1 \times 10^{7}\right.$ cells $\left./ \mathrm{ml}\right)$. A cell resuspension of $200 \mu 1$ $\left(1 \times 10^{6}\right.$ cells) subcutaneously into the right flank of BALB/c nude mice. The animals were randomly divided into three groups (untreated group, control siRNA group and Bmi-1 siRNA group) (5 for each group). Bmi-1 siRNA or control siRNA (100 ng/ $\mu \mathrm{l})$ treatment was not initiated about 2 weeks until tumor volume reached $55-80 \mathrm{~mm}^{3}(16)$, the animals were monitored for tumor inspection every other day after Bmi-1 siRNA treatment and tumor volume $\left(\mathrm{mm}^{3}\right)$ and weight (g) were calculated according to the methods described previously (17).
Immunohistochemical analysis. Tumors were embedded in paraffin, sectioned at 4-6 $\mu \mathrm{m}$, and stained with H\&E. Cell proliferation was assessed by quantification with Ki-67 immunohistochemistry, and Bmi-1 expression was also analyzed by immunohistochemistry. The anti-human Bmi-1 and Ki-67 antibodies were both diluted 1:400 and immunostaining was done on the Dako Autostainer using the Chemicon Mouse-to-Mouse Peroxidase Detection kit (Serologicals, Inc., Temecula, CA). Ki-67-positive cells were scored by visual examination of 40 randomly selected fields of x400 magnification containing at least 2000 cells.

TUNEL assay. The tissue sections were deparaffinized in xylene and rehydrated in graded ethanol and distilled water. After being rinsed thrice with PBS, the slides were incubated with proteinase $\mathrm{K}(20 \mu \mathrm{g} / \mathrm{ml}$ in PBS $)$ for $20 \mathrm{~min}$ at $\mathrm{RT}$, and terminal deoxynucleotidyl transferase dUTP nick end labeling (TUNEL) staining was carried out using in situ cell death detection kit (KeyGen Biotech Ltd., Nanjing, China) according to the manufacture's instructions. TUNEL-positive cells were quantified in 40 randomly selected high-power fields (x400) of each tissue section.

Statistical analysis. For cell proliferation, cell cycle, cell apoptosis, RT-PCR, Western blotting and in vivo tumorigenic assays, values were obtained from three independent experiments as described above. The data were performed by one-way analysis of variance using SPSS version 13.0 (SPSS, Chicago, USA). Summary statistics are expressed as the means \pm standard deviations. In the statistical analyses, a $\mathrm{P}<0.05$ was considered statistically significant and all $\mathrm{P}$-values were two-sided.

\section{Results}

Bmi-1 siRNA down-regulates the Bmi-1 expression and evokes decrease of Akt phosphorylation. It is well known that Akt phosphorylation status and p21 level are tightly associated with cell survival, cell cycle and cell apoptosis in multiple different tumors. In this study, total proteins were extracted at $48 \mathrm{~h}$ from untreated MCF-7 cells transfected with control siRNA and Bmi-1 siRNA, followed by Western blot analysis for expressions of Bmi-1 and p21 proteins and level of Akt phosphorylation. The results showed that expression of Bmi-1 protein in Bmi-1 siRNA group was obviously lower than that in untreated group or control siRNA group $(\mathrm{P}<0.05)$, while expression of $\mathrm{p} 21$ protein was contrary to expression of Bmi-1 protein (Fig. 1). In addition, the levels of Akt phosphorylation at Ser308 and Ser473 were both evidently reduced after Bmi-1 siRNA treatment, while there was no change in the total Akt protein level (Fig. 1). These results indicate that down-regulation of $\mathrm{Bmi}-1$ expression results in the increase of p21 expression and decrease of Akt phosphorylation level. However, the precise mechanism for these events remains to be elucidated.

Bmi-1 siRNA inhibits proliferation of breast carcinoma cells in vitro. Recently, p21 was perceived mainly as an anticancer protein because of its antiproliferative effects (18). The downregulation of Bmi-1 expression mediated the up-regulation of 
A

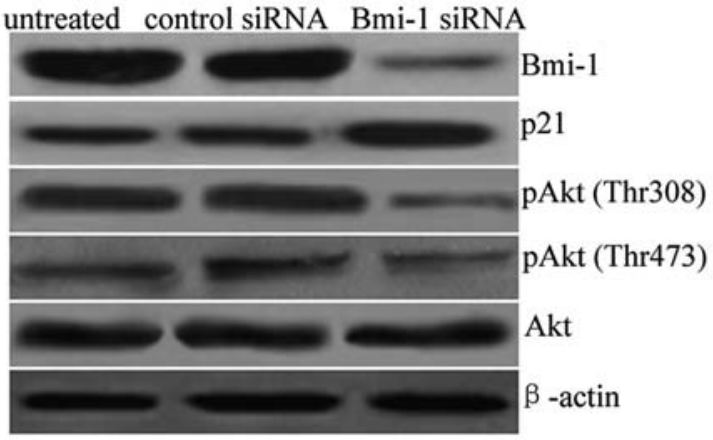

B

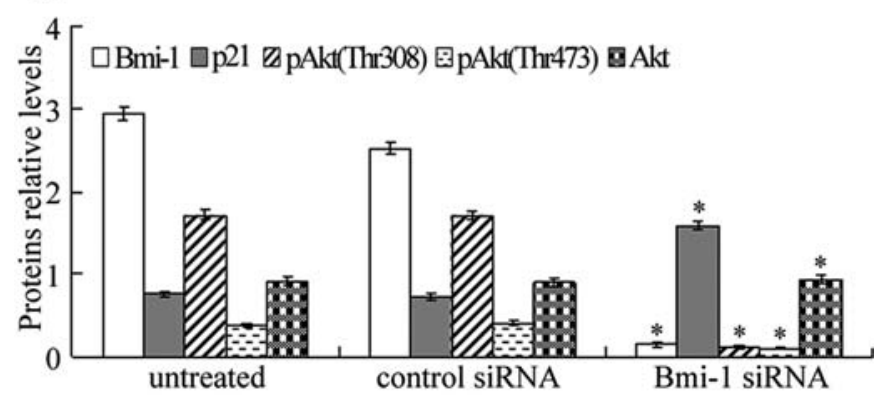

Figure 1. Down-regulation of Akt phosphorylation and an increase in p21 levels mediated by down-regulation of Bmi-1 expression in MCF-7 cells. Breast carcinoma cell line MCF cells untreated and transfected with Bmi-1 siRNA were harvested $48 \mathrm{~h}$ after transfection, and total proteins were isolated with cell lysates, respectively, subsequently, Western blotting was used to analyze the expressions of proteins. (A) Western blot analysis for the expressions of p21, pAkt (Thr308), pAkt (Thr473), total Akt and B-actin proteins (B) Semi-quantitated values of proteins levels of p21, pAkt (Thr308), pAkt (Thr473), total Akt to B-actin, respectively. Results from three independently repeated experiments, which were statistically analyzed by densitometry using Gene Tools software, are expressed as means \pm SD. ${ }^{*} \mathrm{P}<0.05$, compared with untreated and control siRNA group. Here, results of one representative experiment are reported. Levels of $\beta$-actin are shown for equal loading conditions.

p21 expression may be associated with the proliferation of breast carcinoma MCF-7 cells. To elucidate whether Bmi-1 siRNA affects cellular proliferation of breast carcinoma MCF-7 cells, we utilized CCK-8 kit, a kind of viable cell counts, as a substitute for MTT to analyze the effect of downregulation of Bmi-1 expression on proliferation of $\mathrm{MCF}-7$ cells. As shown in Fig. 2, there were no obvious differences in the proliferation of MCF-7 cells untreated and transfected with control siRNA $(\mathrm{P}>0.05)$. However, the growth of MCF-7 cells transfected with Bmi-1 siRNA was inhibited significantly $(\mathrm{P}<0.05)$ compared to that of $\mathrm{MCF}-7$ cells untreated and transfected with control siRNA, which may be tightly associated with up-regulation of p21 expression.

Down-regulation of Bmi-1 expression mediates cell cycle arrest. Cell cycle analysis was carried out using Flow cytometry, the result demonstrated that the percentage of cell numbers in $\mathrm{G}_{0} / \mathrm{G}_{1}$ phase $(67.52 \pm 3.76 \%)$ in Bmi-1 siRNA group was obviously higher than that in untreated $(46.40 \pm 1.85 \%)$ or control siRNA group $(45.41 \pm 1.37 \%)(\mathrm{F}=72.199, \mathrm{P}=0.000)$ (Fig. 3A), suggesting that down-regulation of Bmi-1 expression could arrest cell cycle at $\mathrm{G}_{0} / \mathrm{G}_{1}$ phase. In addition, the percentage of cell numbers in $\mathrm{S}$ phase $(14.85 \pm 2.65 \%)$ in Bmi-1 siRNA group was markedly lower than that in untreated

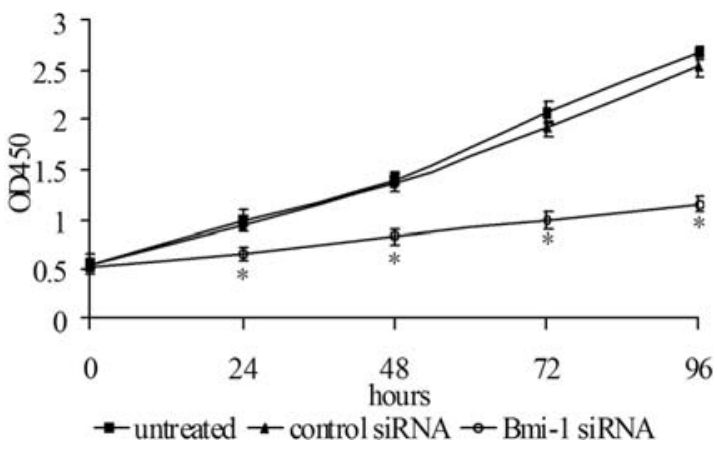

Figure 2. Down-regulation of Bmi-1 expression inhibits the proliferation of MCF-7 cells. MCF-7 cells untreated and transfected with Bmi-1 siRNA were harvested at 24, 48, 72 and $96 \mathrm{~h}$, respectively, and cell proliferations were detected by CCK- 8 kit. MCF-7 cells transfected with Bmi-1 siRNA had a decreased growth rate that was significantly different from MCF-7 cells untreated and transfected with control siRNA, ${ }^{*} \mathrm{P}<0.05$ compared with untreated group and control siRNA group.

$(30.62 \pm 1.86 \%)$ or control siRNA group $(30.69 \pm 2.35 \%)$ $(\mathrm{F}=46.852, \mathrm{P}=0.000)$, indicating that $\mathrm{Bmi}-1$ siRNA resulted in the blockage of DNA synthesis (Fig. 3A). Moreover, in order to explore the possible molecular mechanism of changes of cell cycle distributions, a large number of genes involved in cell cycle kinetics were investigated by RT-PCR and Western blotting methods. The results revealed that expressions of cyclin D1, cyclin E and cdk2 mRNA and proteins were obviously down-regulated compared with untreated group and control siRNA group (Fig. 3B-E). These findings suggest that cell cycle changes may be tightly correlated with aberrant changes of cell cycle related genes, such as cyclin D1, cyclin $\mathrm{E}$ and cdk2.

Flow cytometry analysis for cell apoptosis. It is well known that cell apoptosis play a pivotal role in the occurrence and development of tumors. Whether down-regulation of Bmi-1 expression is involved in the apoptosis of MCF-7 cells. In this study, flow cytometry was utilized to analyze the apoptosis of MCF-7 cells mediated by Bmi-1 siRNA. The results demonstrated that the proportions of early cell apoptosis (region II) $(21.28 \pm 1.71 \%)$ in Bmi-1 siRNA group were evidently higher than that in untreated group $(3.33 \pm 0.20 \%)$ or control siRNA group $(3.48 \pm 0.21 \%)(\mathrm{F}=318.404, \mathrm{P}=0.000)$, and the tendency of total cell apoptosis rates (region II plus III) was consistent with that of early cell apoptosis rate (Fig. 4). However, there was no difference in the early apoptosis rate and total apoptosis rate between MCF-7 cells untreated and transfected with control siRNA $(\mathrm{P}>0.05)$, suggesting the introduction of Bmi-1 siRNA has an obvious inductive effect on apoptosis of MCF-7 cells. Further, to elucidate the possible molecular mechanism of cell apoptosis mediated by Bmi-1 siRNA, we then investigated expressions of bcl-2 and bax tightly associated with cell apoptosis after Bmi-1 siRNA treatment. The results revealed that the expressions of apoptosis inhibitor bcl-2 mRNA and protein in Bmi-1 siRNA group were significantly lower than that in untreated group or control siRNA group, while bax expression was in contrast with bcl-2 expression. Furthermore, Akt has been verified to be a large number of downstream substrates that contribute to 

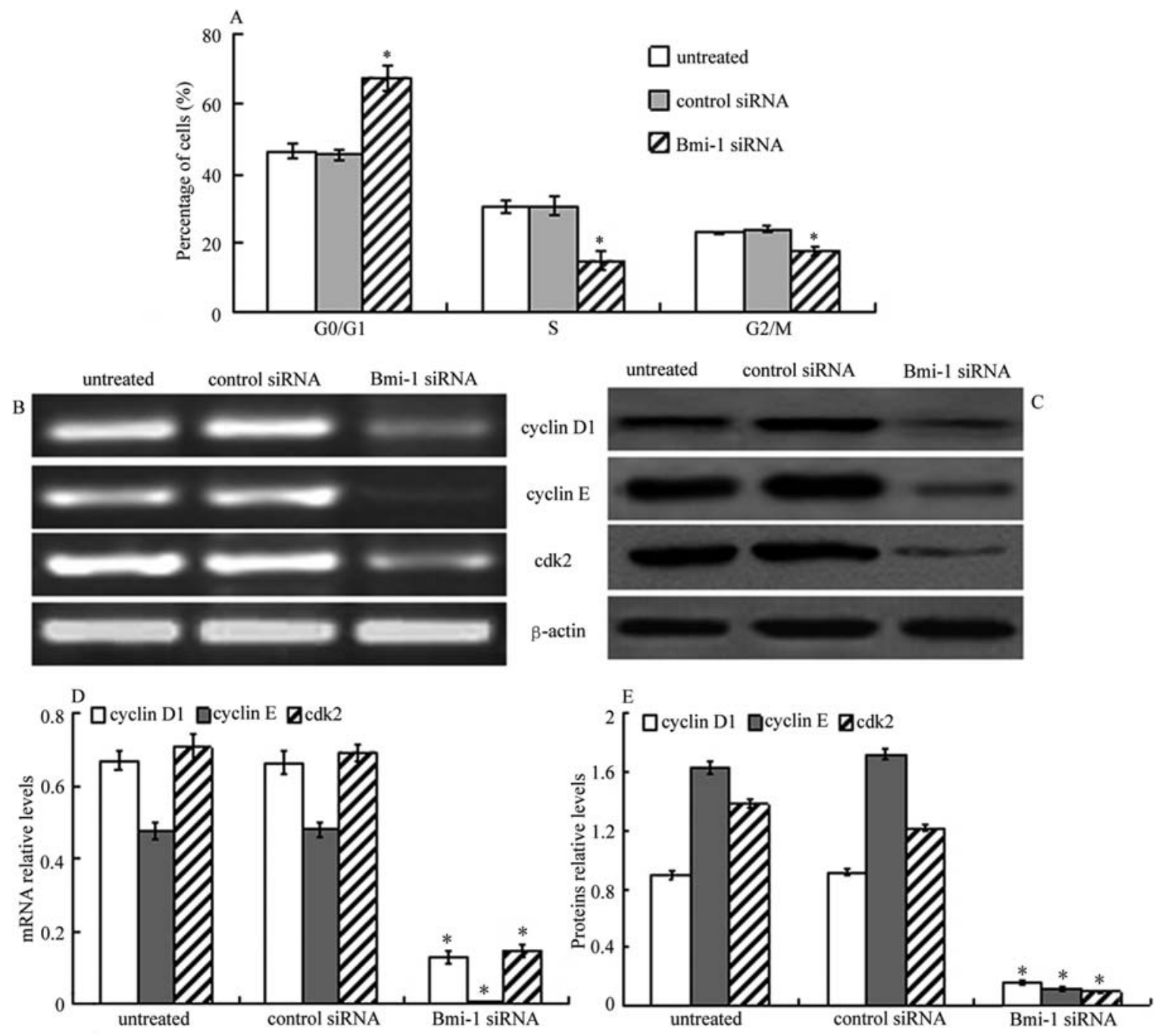

Figure 3. Effect of down-regulation of Bmi-1 expression on distribution of cell cycle and expressions of cell cycle regulatory genes in MCF-7 cells. (A) Effect of down-regulation of Bmi-1 expression on distribution of cell cycle in MCF-7 cells. Results derived from three independent experiments are expressed as means $\pm \mathrm{SD}$. "P $<0.05$, compared with untreated and control siRNA group. (B) Semi-quantitative RT-PCR analysis for the expressions of cyclin D1, cyclin E and cdk2 mRNAs. (C) Western blot analysis for the expressions of cyclin D1, cyclin E and cdk2 proteins. (D) Semi-quantitated values of mRNA levels of cyclin D1, cyclin E, cdk2 to B-actin, respectively. (E) Semi-quantitated values of protein levels of cyclin D1, cyclin E, cdk2 to B-actin, respectively. Results from three independently repeated experiments, which were statistically analyzed by densitometry using Gene Tools software, are expressed as means \pm SD "P<0.05, compared with untreated and control siRNA group. Here, results of one representative experiment are reported. Levels of $\beta$-actin are shown for equal loading conditions.

cell apoptosis (19), therefore, down-regulation of bcl-2 expresion and elevation of bax expression evoked by Bmi-1 siRNA was regulated at least in part by the decrease of Akt phosphorylation level in MCF-7 cells, but the precise mechanism remains to be elucidated. In a word, Bmi-1 mediated cell apoptosis in MCF-7 cells may be tightly associated with the status of Akt phosphorylation and changes of bcl-2 and bax expressions.

Caspase-3/-9 activity analysis. An important component of the apoptotic machinery is the proteolytic system of caspases. Therefore, we investigated the activation of caspase- 3 and caspase- $948 \mathrm{~h}$ after transfection with Bmi-1 siRNA and control siRNA. The results demonstrated that caspase-3/-9 activity significantly increased in Bmi-1 siRNA group compared to that in MCF-7 cells untreated or transfected with control siRNA, there were no differences in the activities of caspase-3/-9 in MCF-7 cells untreated and transfected with control siRNA (Fig. 5), suggesting that Bmi-1 siRNA mediated cell apoptosis at least in part contribute to the increase of activities of caspase-3/-9.

The inhibitory effect of down-regulation of Bmi-1 expression on tumor formation in nude mice. To further verify the downregulation of Bmi-1 expression mediated the proliferation inhibition in vivo, MCF-7 cells implanted into the right flank of nude mice developed palpable tumors after 2 weeks (Fig. 6A), and the volumes of the animals were monitored for tumor inspection every other day after Bmi-1 sRNA treatment. The results revealed that there was an obviously decrease in the volumes and weights of tumors in Bmi-1 siRNA group, compared to that in the untreated or control siRNA groups (Fig. 6B-D) $(\mathrm{P}<0.05)$. However, there was no difference between untreated and control siRNA group in 

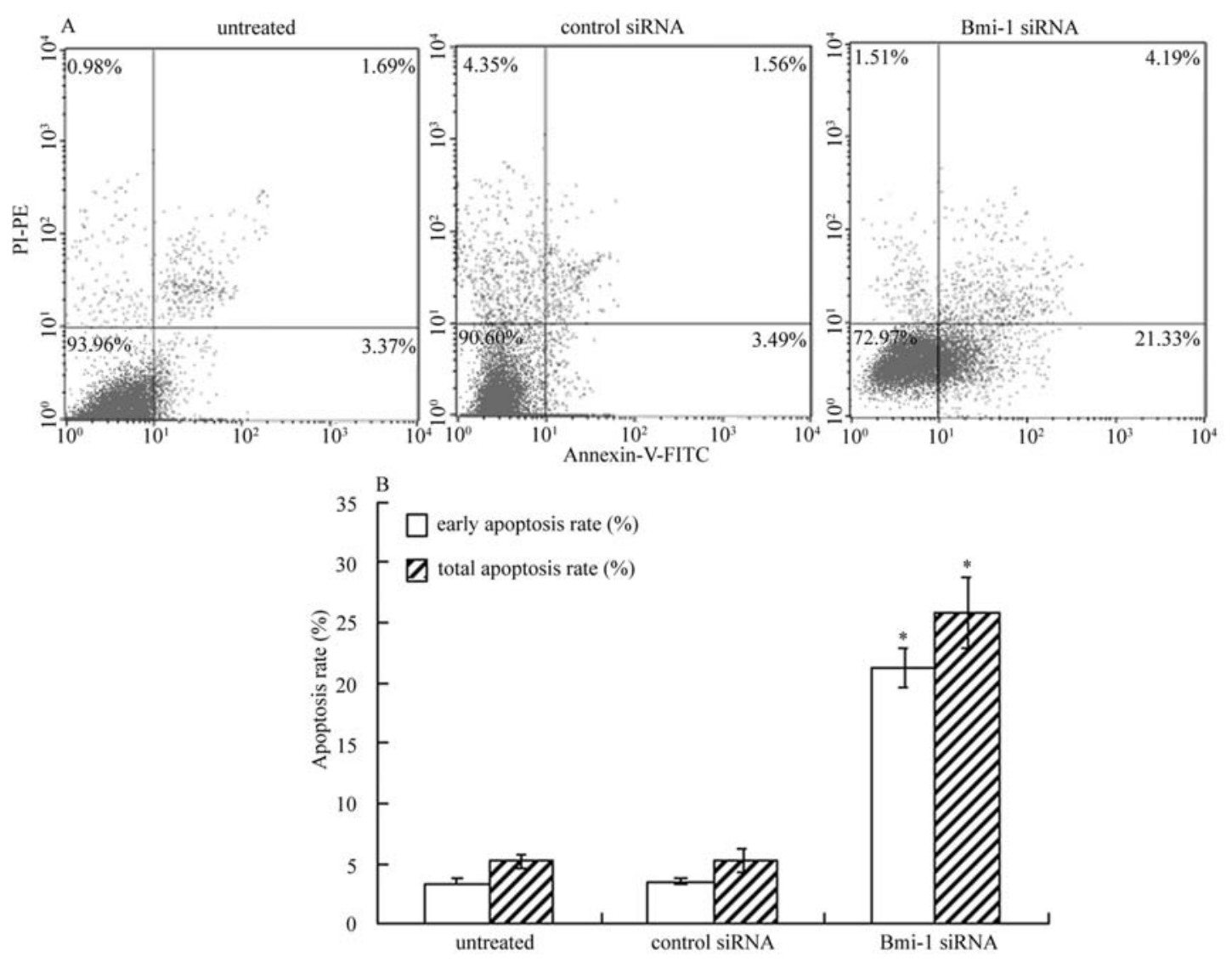

C

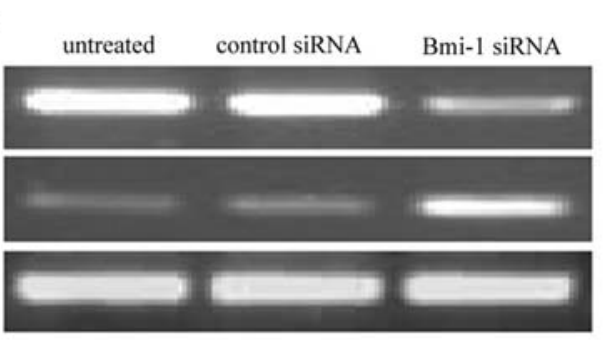

D
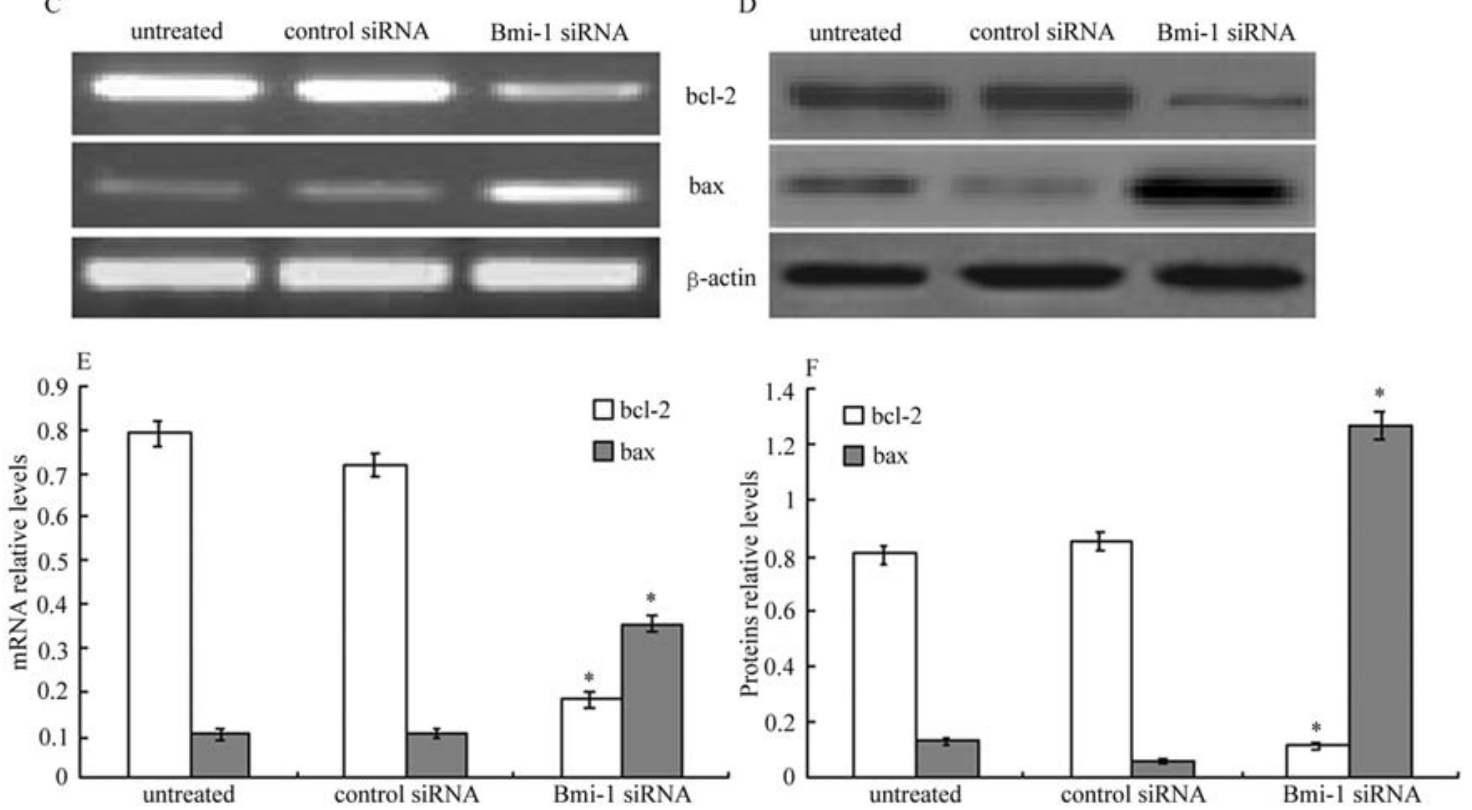

Figure 4. Effect of down-regulation of Bmi-1 expression on cell apoptosis and expressions of cell apoptosis related genes in MCF-7 cells. (A) Effect of downregulation of Bmi-1 expression on cell apoptosis in MCF-7 cells. The result of one representative experiment is presented; (B) The results of statistical analysis of cell apoptosis. Results derived from three independent experiments are expressed as means $\pm \mathrm{SD}$. ${ }^{*} \mathrm{P}<0.05$, compared to those of MCF-7 untreated and transfected with control siRNA. (C) Semi-quantitative RT-PCR analysis for the expressions of bcl-2 and bax mRNAs. (D) Western blot analysis for the expressions of bcl-2 and bax proteins. (E) Semi-quantitated values of mRNA levels of bcl-2, bax to B-actin, respectively. (F) Semi-quantitated values of proteins levels of bcl-2, bax to $\beta$-actin, respectively. Results from three independently repeated experiments, which were statistically analyzed by densitometry using Gene Tools software, are expressed as means $\pm \mathrm{SD}$. ${ }^{*} \mathrm{P}<0.05$, compared with untreated and control siRNA group. Here, results of one representative experiment are reported. Levels of $\beta$-actin are shown for equal loading conditions.

the volumes and weights of tumors (Fig. 6B-D) $(\mathrm{P}>0.05)$, suggesting Bmi-1 down-regulation could significantly inhibit the tumor formation. Combined with the results in vitro, our data presented here demonstrate that Bmi-1 may be a potential molecular target for the therapy of breast carcinoma. 


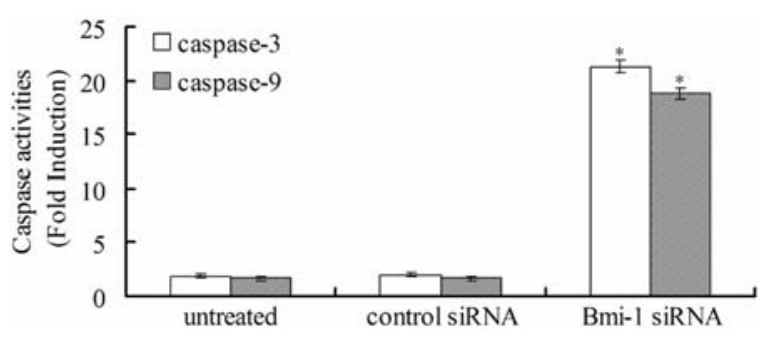

Figure 5. The increase of caspase-3/-9 activities evoked by down-regulation of Bmi-1 expression. Ac-DEVD-AMC and Ac-LEHD-AFC were used for substrates of caspase-3 and -9 , respectively. Caspase activities were analyzed as described in Materials and methods. Results from three independently repeated experiments are expressed as means $\pm \mathrm{SD}$. ${ }^{*} \mathrm{P}<0.05$, compared with untreated group and control siRNA group.

Bmi-1 siRNA down-regulates the expression of Bmi-1 and decreases proliferation but increases apoptosis of breast carcinoma cells in vivo. To verify whether the Bmi-1 siRNA could down-regulate the Bmi-1 expression in vivo, immunohistochemistry was used to analyze the Bmi-1 expression in the tissues of nude mice. The results demonstrated that Bmi-1 expression was obviously down-regulated compared with untreated group and control siRNA group $(\mathrm{P}<0.05)($ Fig. 7A). Further, to quantitatively compare the proliferation and apoptotic index of tumors treated with Bmi-1 siRNA, the tumor sections were stained for expression of Ki-67 and TUNEL assay, respectively. As shown in Fig. 7A, Bmi-1
siRNA treatment significantly decreases the number of Ki-67positive cells in tumors compared with untreated group and control siRNA. Based on the counting of 40 randomly selected microscopic fields, the proliferation index was decreased from $86.35 \pm 3.47 \%$ in the untreated group, $83.89 \pm 4.39 \%$ in control siRNA group to $43.71 \pm 3.16 \%$ in Bmi-1 siRNA-treated tumors (Fig. 7B). In contrast to the proliferation index, Bmi-1 siRNA-treated tumors compared with untreated group and control siRNA group showed increased numbers of apoptotic cells with condensed and irregularly shaped nuclei, staining positively for TUNEL (Fig. 7A). Based on the counting of randomly selected microscopic fields, the number of apoptotic cells was increased from $9 \pm 3$ per 10 high-power microscopic fields in untreated group, $11 \pm 4$ to $93 \pm 11$ in Bmi-1 siRNAtreated tumors (Fig. 7C). The changes in both proliferation and apoptosis indexes were statistically significant among three groups (both $\mathrm{P}<0.05$ ).

\section{Discussion}

Bmi-1 was originally discovered as an oncogene that cooperated with c-Myc in the initiation of lymphoma in murine models $(20,21)$. Bmi-1 may be new diagnostic and prognostic marker in multiple different tumors including medulloblastoma (22), tongue squamous cell carcinoma (23), colon carcinoma (24), breast carcinoma (11), bladder carcinoma (25). However, precise molecular regulation mechanism of Bmi-1 in breast carcinoma remains elusive, promting the authors to investigate the possible molecular
A

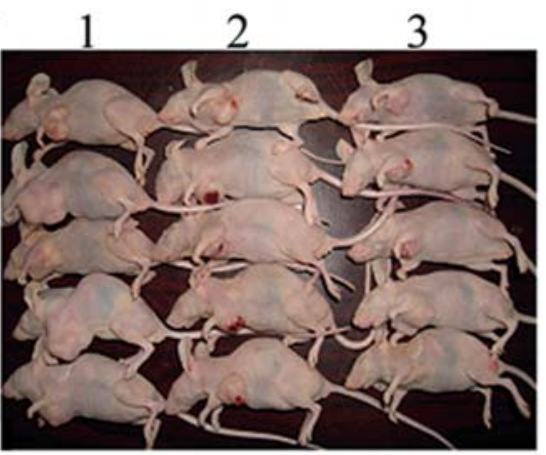

$\mathrm{C}$

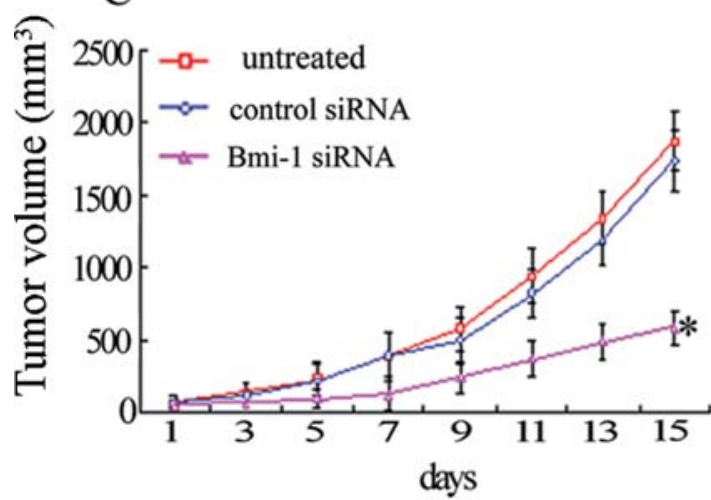

B

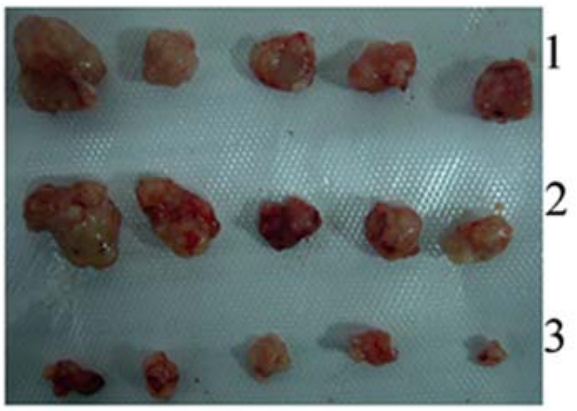

D

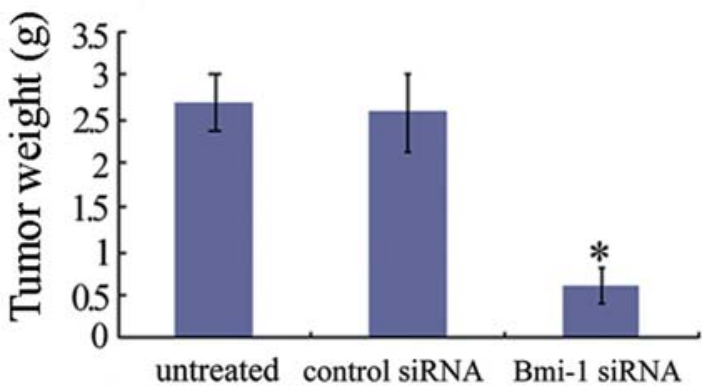

Figure 6. Tumor suppression observed in breast carcinoma MCF-7 xenografts. (A) Examples of tumor suppression in untreated, control siRNA and Bmi-1 siRNA-treated tumors; (B) Tumors from MCF-7 xenografts 2 weeks after treatment with different ways; (C) Tumor volumes from MCF-7 xenografts of each group were assessed every other day, as described in tumorigenicity in nude mice; (D) Tumor weights were measured 2 weeks after the treatments. One-way analysis of variance was used to determine the differences among the groups. 1, untreated group; 2, control siRNA group; 3 , Bmi-1 siRNA group. 


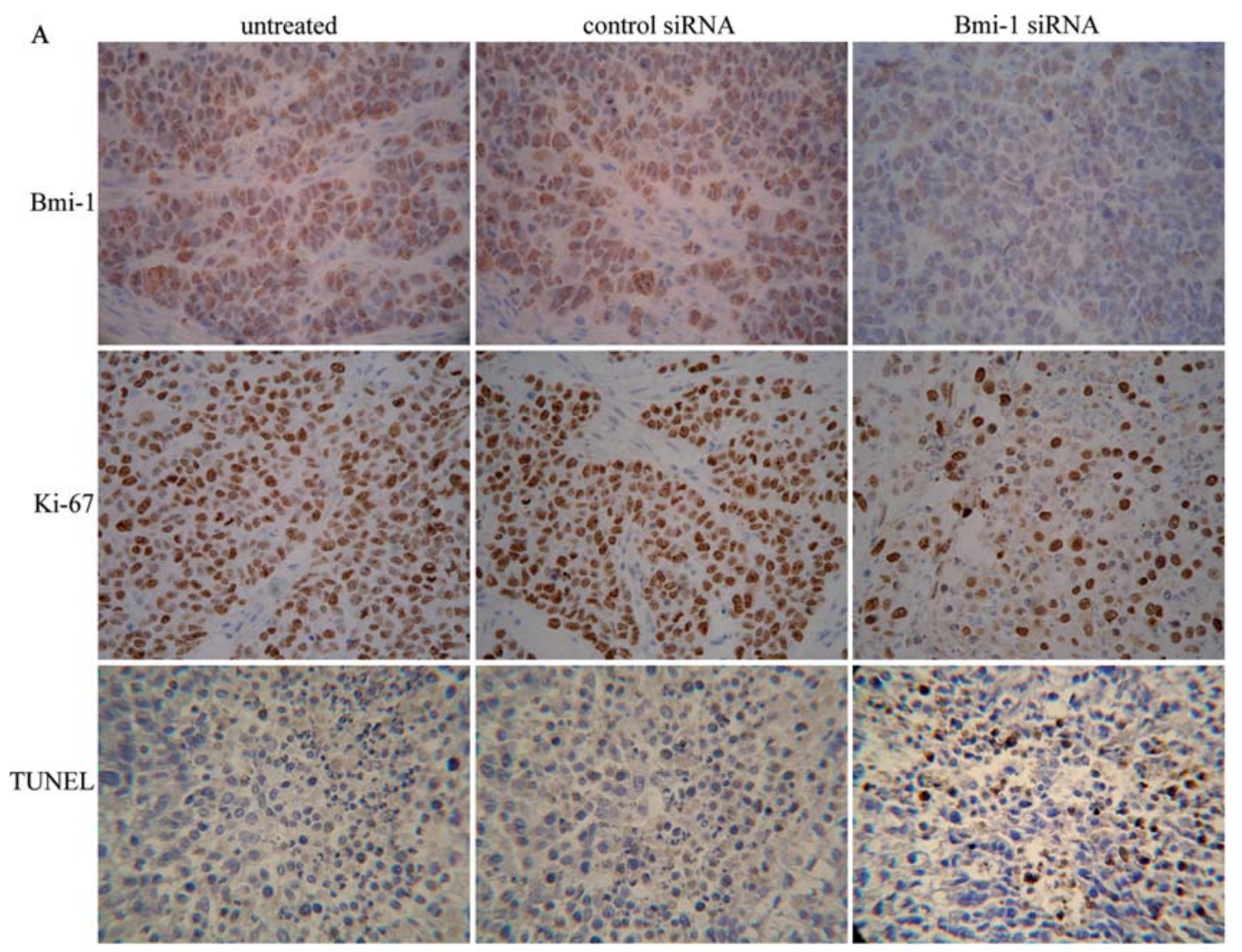

B

C
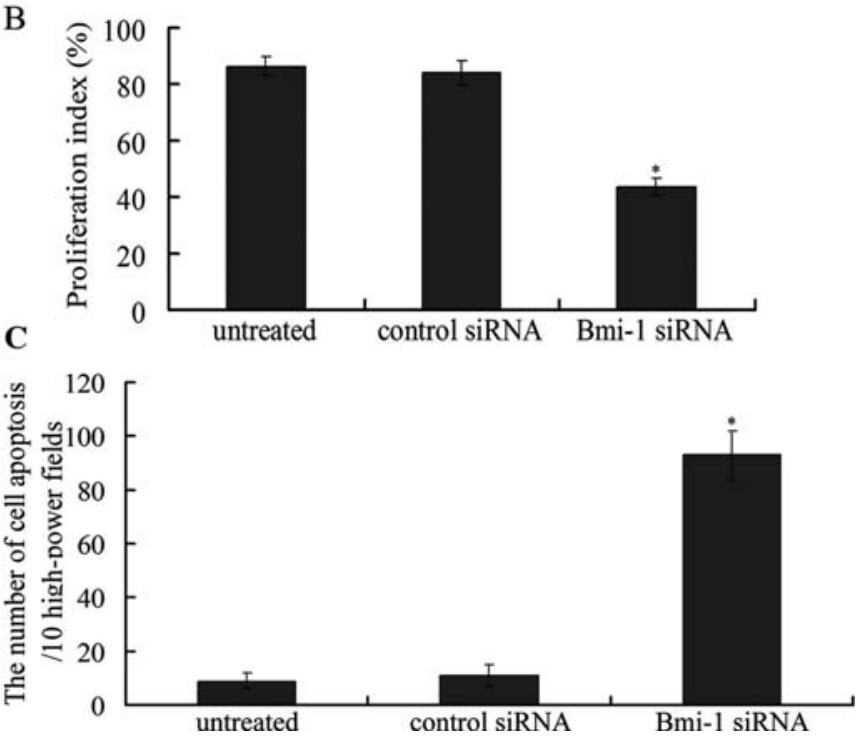

mechanism of Bmi-1 in occurrence and development of breast carcinoma.

It is well documented that Bmi-1 plays important roles in cell cycle regulation, cell immortalization and cell senescence (26). Previous studies have suggested that Bmi-1 may enhance cell survival by regulating the level of cell cycle regulatory genes $(7,27,28)$. Lee et al found overexpression of Bmi-1 was associated with increased levels of cyclin D1, cyclin-dependent kinases such as cdk2 and cdk4 (29). The absence of modulation of Bmi-1 level is consistent with a recent report in SCC-4 oral cancer cells, where cell growth was slowed by siRNA knockdown of Bmi-1 expression (9).
Figure 7. Effect of down-regulation of Bmi-1 expression on proliferation and apoptosis of tumor cells of MCF-7 xenografts. (A) Immunohistochemistry analysis for the expressions of Bmi-1 and Ki-67 and TUNEL assays was used to investigate the cell apoptosis in the tumor cells of MCF-7 xenografts. Representative micrographs of tumors untreated and treated with control siRNA and Bmi-1 siRNA for two weeks are presented; (B) Proliferation index calculated as the ratio of Ki-67-positive cells to the total cells in the selected microscopic fields, ${ }^{*} \mathrm{P}<0.05$, compared with untreated tumors and control siRNA treated tumors; (C) The number of cell apoptosis assessed as number of positive cells per 10 high-power fields, ${ }^{*} \mathrm{P}<0.05$, compared with untreated tumors and control siRNA treated tumors.

All the studies mentioned above have suggested that Bmi-1 was closely correlated with cell proliferation and cell cycle of tumors. However, to date, effect of Bmi-1 siRNA on cell proliferation and cell cycle in breast carcinoma cells remains ill-defined. In the present study, our data showed that Bmi-1 siRNA could markedly inhibit cell proliferation in MCF-7 cells. The results of cell cycle analysis suggested that Bmi-1 siRNA could arrest cell cycle at $\mathrm{G}_{0} / \mathrm{G}_{1}$ phases and inhibit DNA synthesis, however, to clarify whether Bmi-1 mediated proliferation inhibition and cell cycle arrest of MCF-7 cells were involved in changes of a series of cell cycle regulatory genes, we investigated the expressions of a large number of genes involved with cell cycle kinetics including p21, cyclin D1, cyclin E and cdk2, we found that Bmi-1 siRNA resulted in a decrease in cyclin D1, cyclin E and cdk2 levels, whereas a increase in p21 level, which might have a direct relevance to cell proliferation inhibition and $\mathrm{G}_{0} / \mathrm{G}_{1}$ phase arrest observed in MCF-7 cells.

Apoptosis, the process of programmed cell death, is governed by complex, gene-directed pathways, and is involved in expressions changes of a series of genes (30). Dysregulation of apoptosis plays a key role in tumorigenesis and 
can allow tumor cells to become resistant to anticancer treatments (30). Akt/protein kinase B (PKB) plays a critical role in controlling the balance between cell survival and apoptosis (31). Akt regulates cellular survival and metabolism by binding and regulating many downstream effectors, e.g. nuclear factor-кB, bcl-2 family proteins and murine double minute 2 (MDM2) (32). In addition, the high level of expression of phosphorylated Akt correlated with Ki-67 cell proliferation activity and inhibitors of apoptosis, suggesting decrease of Akt phosphorylation level induces cell apoptosis. In the current study, the results of flow cytometry revealed that Bmi-1 siRNA could induce cell apoptosis in MCF-7 cells, meanwhile, to elucidate the possible mechanism of MCF-7 cell apoptosis, the levels of Akt phosphorylation at Ser308 and Ser473 were detected using Western blotting method. The results demonstrated that down-regulation of Bmi-1 expression obviously gave rise to the decrease of the levels of Akt phosphorylation at Ser308 and Ser473, suggesting Bmi-1 siRNA mediated MCF-7 cell apoptosis may be tightly associated with reduced level of Akt phosphorylation. Additionally, caspase-3 works downstream of Akt in the cell signaling pathway, subsequently leading cells to undergo apoptosis (33), once phosphorylated, Akt is released from the cell membrane and migrates to intracellular locations where Akt can activate other proteins, resulting in the suppression of cellular apoptosis. Activated Akt leads to cellular survival by several mechanisms, including suppressing caspase-9 and caspase-3 activation (34). To further verify the decrease of Akt phosphorylation level-mediated cell apoptosis of breast carcinoma, the activities of caspase- 3 and caspase- 9 and expressions of bcl-2 and bax were analyzed, the results suggested that Bmi-1 siRNA markedly increased the activities of caspase- 3 and caspase- 9 and expression of bax, but reduced the expression of bcl-2. These findings suggest that down-regulation of Bmi-1 expression mediated cell apoptosis of breast carcinoma was tightly associated with the decrease of Akt phosphorylation level, followed by increase of the activities of caspase- 3 and caspase- 9 and expression of bax, and decrease of bcl-2.

Given the role of Bmi-1 in breast carcinoma in vitro, we investigated whether the same effect appears in vivo. Our results demonstrated that Bmi-1 effectively inhibited the proliferation of tumors in nude mice. The expression of the human Ki-67 protein is strictly associated with cell proliferation. The Ki-67 index is the best available marker of proliferation because it is not involved in DNA repair process as proliferation cell nuclear antigen (PCNA). High Ki-67 expression was also significantly and independently associated with decreased survival, in accordance with the findings of other studies (35). In this study, we evaluated the $\mathrm{Ki}-67$ expression representing the fraction of cellular proliferation to prove Bmi-1 siRNA mediated proli-feration inhibition. Our results demonstrated that Bmi-1 siRNA treatment significantly decreases the number of Ki-67positive cells in tumors of nude mice compared with untreated group and control siRNA, and the proliferation index was obviously decreased after treatment of Bmi-1 siRNA. In contrast to the proliferation index, Bmi-1 siRNA-treated tumors compared with untreated group and control siRNA group showed increased numbers of apoptotic cells. These results mentioned above suggest that down-regulation of Bmi-1 expression evokes cell proliferation inhibition closely associated with decrease of Ki-67 expression and cell apoptosis in vivo.

In conclusion, we found the down-regulation of Bmi-1 expression inhibits the proliferation of breast carcinoma cells in vitro and in vivo, followed by cell cycle arrest and cell apoptosis, which may be tightly associated with changes of cell cycle and apoptosis-related genes, which will provide important insights into the role of Bmi-1 in occurrence and development of breast carcinoma, in the hope that manipulation of Bmi-1 will provide the potential molecular target for therapy of breast carcinoma.

\section{References}

1. Parkin DM, Bray FI and Devesa SS: Cancer burden in the year 2000. The global picture. Eur J Cancer 37 (Suppl. 8): S4-S66, 2001.

2. Jemal A, Siegel R, Ward E, Hao Y, Xu J, Murray T and Thun MJ: Cancer statistics, 2008. CA Cancer J Clin 58: 71-96, 2008.

3. Gasparini G, Longo R, Torino F and Morabito A: Therapy of breast cancer with molecular targeting agents. Ann Oncol 16 (Suppl. 4): iv28-36, 2005.

4. Valk-Lingbeek ME, Bruggeman SW and van Lohuizen M: Stem cells and cancer; the polycomb connection. Cell 118: 409-418, 2004.

5. Van der Lugt NM, Domen J, Linders K, et al: Posterior transformation, neurological abnormalities, and severe hematopoietic defects in mice with a targeted deletion of the bmi-1 proto-oncogene. Genes Dev 8: 757-769, 1994.

6. Vonlanthen S, Heighway J, Altermatt HJ, Gugger M, Kappeler A, Borner MM, van Lohuizen M and Betticher DC: The bmi-1 oncoprotein is differentially expressed in non-small cell lung cancer and correlates with INK4A-ARF locus expression. Br J Cancer 84: 1372-1376, 2001.

7. Kim JH, Yoon SY, Kim CN, Joo JH, Moon SK, Choe IS, Choe YK and Kim JW: The Bmi-1 oncoprotein is overexpressed in human colorectal cancer and correlates with the reduced p16INK4a/p14ARF proteins. Cancer Lett 203: 217-224, 2004.

8. Song LB, Li J, Liao WT, Feng Y, Yu CP, Hu LJ, Kong QL, Xu LH, Zhang X, Liu WL, Li MZ, Zhang L, Kang TB, Fu LW, Huang WL, Xia YF, Tsao SW, Li M, Band V, Band H, Shi QH, Zeng YX and Zeng MS: The polycomb group protein Bmi-1 represses the tumor suppressor PTEN and induces epithelialmesenchymal transition in human nasopharyngeal epithelial cells. J Clin Invest 119: 3626-3636, 2009.

9. Kang MK, Kim RH, Kim SJ, Yip FK, Shin KH, Dimri GP, Christensen R, Han T and Park NH: Elevated Bmi-1 expression is associated with dysplastic cell transformation during oral carcinogenesis and is required for cancer cell replication and survival. Br J Cancer 96: 126-133, 2007.

10. Wang JF, Liu Y, Liu WJ and He SY: Expression of Bmi-1 gene in esophageal carcinoma cell EC9706 and its effect on cell cycle, apoptosis and migration. Chin J Cancer 29: 689-696, 2010.

11. Saeki M, Kobayashi D, Tsuji N, Kuribayashi K and Watanabe N: Diagnostic importance of overexpression of Bmi-1 mRNA in early breast cancers. Int J Oncol 35: 511-515, 2009.

12. Choi YJ, Choi YL, Cho EY, Shin YK, Sung KW, Hwang YK, Lee SJ, Kong G, Lee JE, Kim JS, Kim JH, Yang JH and Nam SJ: Expression of Bmi-1 protein in tumor tissues is associated with favorable prognosis in breast cancer patients. Breast Cancer Res Treat 113: 83-93, 2009.

13. Li K, He W, Lin N, Wang X and Fan QX: Down-regulation of $\mathrm{N}$-cadherin expression inhibits invasiveness, arrests cell cycle and induces cell apoptosis in esophageal squamous cell carcinoma. Cancer Invest 28: 479-486, 2010.

14. Jiao J, Qin Z, Li S, Liu H and Lu Z: Potential role of Notch1 signaling pathway in laryngeal squamous cell carcinoma cell line Hep-2 involving proliferation inhibition, cell cycle arrest, cell apoptosis, and cell migration. Oncol Rep 22: 815-823, 2009.

15. Hou G, Zhang Q, Wang L, Liu M, Wang J and Xue L: mTOR inhibitor rapamycin alone or combined with cisplatin inhibits growth of esophageal squamous cell carcinoma in nude mice. Cancer Lett 290: 248-254, 2010. 
16. Smolewski P: Recent developments in targeting the mammalian target of rapamycin (mTOR) kinase pathway. Anticancer Drugs 17: 487-494, 2006

17. Quidville V, Segond N, Tebbi A, Cohen R, Jullienne A, Lepoivre $\mathrm{M}$ and Lausson $\mathrm{S}$ : Anti-tumoral effect of a celecoxib low dose on a model of human medullary thyroid cancer in nude mice. Thyroid 19: 613-621, 2009.

18. Zupkovitz G, Grausenburger R, Brunmeir R, Senese S, Tischler J, Jurkin J, Rembold M, Meunier D, Egger G, Lagger S, Chiocca S, Propst F, Weitzer G and Seiser C: The cyclin-dependent kinase inhibitor p21 is a crucial target for histone deacetylase 1 as a regulator of cellular proliferation. Mol Cell Biol 30: 1171-1181, 2010.

19. Nicholson KM and Anderson NG: The protein kinase B/Akt signalling pathway in human malignancy. Cell Signal 14: 381-395, 2002.

20. Haupt Y, Alexander WS, Barri G, Klinken SP and Adams JM: Novel zinc finger gene implicated as myc collaborator by retrovirally accelerated lymphomagenesis in E mu-myc transgenic mice. Cell 65: 753-763, 1991.

21. Van Lohuizen M, Verbeek S, Scheijen B, Wientjens E, van der Gulden $\mathrm{H}$ and Berns A: Identification of cooperating oncogenes in $\mathrm{E}$ mu-myc transgenic mice by provirus tagging. Cell 65: 737-752, 1991

22. Venkataraman S, Alimova I, Fan R, Harris P, Foreman N and Vibhakar R: MicroRNA 128a increases intracellular ROS level by targeting Bmi-1 and inhibits medulloblastoma cancer cell growth by promoting senescence. PLoS One 5: e10748, 2010.

23. Hayry V, Makinen LK, Atula T, Sariola H, Makitie A, Leivo I, Keski-Santti H, Lundin J, Haglund C and Hagstrom J: Bmi-1 expression predicts prognosis in squamous cell carcinoma of the tongue. Br J Cancer 102: 892-897, 2010.

24. Li DW, Tang HM, Fan JW, Yan DW, Zhou CZ, Li SX, Wang XL and Peng ZH: Expression level of Bmi-1 oncoprotein is associated with progression and prognosis in colon cancer. J Cancer Res Clin Oncol 136: 997-1006, 2010.

25. Qin ZK, Yang JA, Ye YL, Zhang X, Xu LH, Zhou FJ, Han H, Liu ZW, Song LB and Zeng MS: Expression of Bmi-1 is a prognostic marker in bladder cancer. BMC Cancer 9: 61, 2009.
26. Dhawan S, Tschen SI and Bhushan A: Bmi-1 regulates the Ink4a/Arf locus to control pancreatic beta-cell proliferation. Genes Dev 23: 906-911, 2009.

27. Molofsky AV, Pardal R, Iwashita T, Park IK, Clarke MF and Morrison SJ: Bmi-1 dependence distinguishes neural stem cell self-renewal from progenitor proliferation. Nature 425: 962-967, 2003.

28. Park IK, Qian D, Kiel M, Becker MW, Pihalja M, Weissman IL, Morrison SJ and Clarke MF: Bmi-1 is required for maintenance of adult self-renewing haematopoietic stem cells. Nature 423: 302-305, 2003.

29. Lee K, Adhikary G, Balasubramanian S, Gopalakrishnan R, McCormick T, Dimri GP, Eckert RL and Rorke EA: Expression of Bmi-1 in epidermis enhances cell survival by altering cell cycle regulatory protein expression and inhibiting apoptosis. J Invest Dermatol 128: 9-17, 2008.

30. Reed JC: Apoptosis-targeted therapies for cancer. Cancer Cell 3: $17-22,2003$

31. Franke TF, Kaplan DR and Cantley LC: PI3K: downstream AKTion blocks apoptosis. Cell 88: 435-437, 1997.

32. Song G, Ouyang $G$ and Bao S: The activation of Akt/PKB signaling pathway and cell survival. J Cell Mol Med 9: 59-71, 2005.

33. Kulik G, Carson JP, Vomastek T, Overman K, Gooch BD, Srinivasula S, Alnemri E, Nunez G and Weber MJ: Tumor necrosis factor alpha induces BID cleavage and bypasses antiapoptotic signals in prostate cancer LNCaP cells. Cancer Res 61: 2713-2719, 2001

34. Kelley TW, Graham MM, Doseff AI, Pomerantz RW, Lau SM, Ostrowski MC, Franke TF and Marsh CB: Macrophage colonystimulating factor promotes cell survival through Akt/protein kinase B. J Biol Chem 274: 26393-26398, 1999.

35. Vogt T, Zipperer KH, Vogt A, Holzel D, Landthaler M and Stolz W: p53-protein and Ki-67-antigen expression are both reliable biomarkers of prognosis in thick stage I nodular melanomas of the skin. Histopathology 30: 57-63, 1997. 